\title{
O ENSINO E O MOVIMENTO DE GRAMATIZAÇÃO NO RIO GRANDE DO SUL
}

\author{
Rosaura Albuquerque (UFSM)
}

\begin{abstract}
RESUMO: O presente trabalho tem como tema o movimento de gramatização do Rio Grande do Sul focalizando a constituição do saber metalinguístico e a constituição da língua portuguesa nas terras do extremo Sul do país no final do século XVIII e início do século XIX vinculado à constituição de uma língua nacional e ao seu ensino, às lutas pela posse do território, à vizinhança com os países latinos e à constituição do cidadão. Os dados desse trabalho são de uma pesquisa bibliográfica apoiada nos principais autores: Luís Augusto Fischer (2004), Neto Kraemer (1969) e Regina Portella Schneider (1993). Está divido em dois grandes momentos: o ensino no Rio Grande do Sul: no período que antecedeu a Revolução Farroupilha (início do século XIX até 1835), durante a Revolução Farroupilha (1835 - 1844) e após o período revolucionário e o movimento de gramatização.
\end{abstract}

PALAVRAS-CHAVE: Gramatização. Ensino. Rio Grande do Sul.

ABSTRACT: The present paper has as theme the movement of gramatization in Rio Grande do Sul, focusing on the constitution of metalinguistic knowledge and the Portuguese language constitution in extreme south territory of the country in the end of century XVIII, and in the beginning of century XIX bound to the constitution of a national language and to its teaching, to the battles to possess territory, to the proximity with Latin countries and to the constitution of citizen. The data of this paper comes from a bibliographic research supported on the main authors: Luiís Augusto Fischer (2004), Neto Kraemer (1969), Regina Portella Schneider (1993). It is fragmented in two great moments: the teaching in Rio Grande do Sul: on the period that happened the Farroupilha revolution (beginning of the XIX century until 1835), durinf the Farroupilha revolution (1835-1844) and after the revolutionary period and the movement of gramatization.

KEYWORDS: Gramatization; Teaching. Rio Grande do Sul.

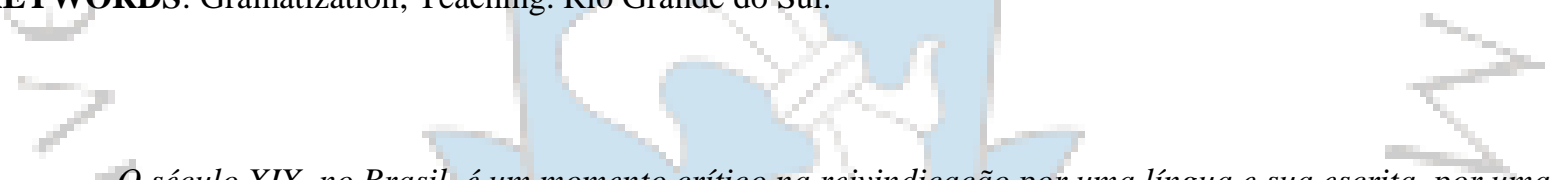

O século XIX, no Brasil, é um momento crítico na reivindicação por uma língua e sua escrita, por uma literatura e sua escrita, por instituições capazes de assegurar a legitimidade e a unidade desses objetos simbólicos sócio-históricos que constituem a materialidade de uma prática que significa a cidadania. (História das Ideias Linguísticas: construção do saber e a constituição da língua nacional, Orlandi (org.)

\section{INTRODUÇÃO}

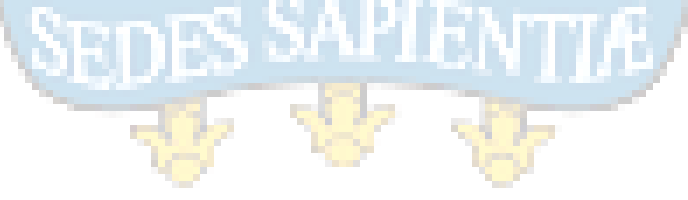

Este artigo aborda o movimento de gramatização no Rio Grande do Sul, tendo como foco de interesse o período que vai do século XVIII e início do século XIX. O objetivo é conhecer como se desenvolveu esse saber sobre a formação da língua portuguesa nesse território do extremo Sul do Brasil. 


\section{Linguagens}

Traçamos, então, nesta reflexão, uma breve incursão histórica do ensino no território gaúcho com um panorama histórico do e no movimento de gramatização em terras gaúchas. Dividimos esse artigo em dois momentos, balizados pela Guerra dos Farrapos, chamada de Revolução Farroupilha - fato histórico marcante no sul do país tanto no traçado do território brasileiro quanto na constituição de cidadania no Rio Grande do Sul "pela formulação de um sentimento localista muito forte" (FISCHER, 2004, p. 13). Distinguimos localista, conforme o sentido empregado por Fischer, do gauchismo exacerbado, ou seja, "de virtude, honra e bravura [que] foram manipulados em nível do simbólico imaginário e tais valores fora especialmente exaltados nos líderes da classe dominante que estiveram à frente da rebelião de 1835" (LOPEZ, 1992).

A conquista do território, a constituição do cidadão gaúcho e a história do ensino de língua são fatos que se mesclam, pois o Rio Grande do Sul fez parte de um território sob o domínio da bandeira espanhola com a adoção dessa língua; posteriormente, a coroa portuguesa passou a usar a língua portuguesa. Foi um território em que ocorreram episódios históricos singulares que despertaram no povo gaúcho - geograficamente mais próximo do Prata (Uruguai e Argentina) do que da metrópole brasileira - um sentimento muito forte de patriotismo, de independência e de nação.

Para alcançarmos o objetivo proposto, a seguir aborda-se a educação no Rio Grande do Sul no período da Revolução Farroupilha, antes e pós Revolução, os métodos e as reformas de ensino, as gramáticas produzidas no Estado - movimentos de linguagem e de educação.

\section{O ENSINO NO RIO GRANDE DO SUL}

\subsection{Período anterior a Revolução Farroupilha (início do século XIX até 1835)}

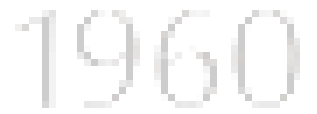

Linguagens \& Cidadania, v. 19, jan./dez., 2017. 


\section{S Linguagens}

A educação, no Rio Grande do Sul, deve muito aos jesuítas espanhóis que fundaram as primeiras escolas para ensinar ler, escrever e contar, surgidas nas primitivas Reduções ${ }^{1}$ que, pelo Tratado de Tordesilhas, cabia à Espanha (PORTO, 1954), confirmando-se que a preocupação com as questões de língua começa com as questões de evangelização. O ensino nas Missões ${ }^{2}$ era bem estruturado, os índios dispunham de um preceptor professor índio que ensinava sob a orientação de um missionário espanhol. Nessas missões, além do guarani, que os padres reduziram a língua escrita, organizando gramática e vocabulários, aprendiam as crianças o espanhol e muitos o latim, o que levou Cardiel a afirmar que 'alguns leem com notável destreza língua estranha melhor do que nós' (FISCHER, 2004, p. 17).

Dois acontecimentos políticos foram marcantes no ensino da língua portuguesa. Um deles foi o Tratado de Madri, assinado entre Portugal e Espanha, que extinguia os Sete Povos, o que fez com que os jesuítas passassem para o lado espanhol e abandonassem o trabalho educativo que desenvolviam. O outro, a política de Marquês de Pombal que expulsou os jesuítas do Brasil, determinando, nas escolas, o ensino do português ao mesmo tempo em que proibia o ensino das línguas dos índios. Era necessário impor a língua "civilizada" à comunidade da colônia, tornando, assim, a língua portuguesa como língua oficial em todo território brasileiro.

A política pombalina vinha, assim, ao encontro dos interesses da coroa portuguesa, uma vez que a religião e o conhecimento da língua portuguesa constituíam instrumentos necessários para o trabalho de civilização e de dominação dos índios no Brasil. Em razão disso, El-Rei, através do alvará de 30/09/1770, determina que:

dada a importância da correção das línguas nacionais para o desenvolvimento dos povos civilizados, por dependerem dela a clareza, a energia e majestade com que deveriam ser estabelecidas as leis, persuadir a verdade da religião e fazer úteis e agradáveis os escritos - nos seus reinos e Domínios os mestres da Língua Latina instituíssem seus discípulos na Gramática Portuguesa, composta por Antônio José dos Reis Lobato, e que nas escolas de ler e escrever fosse abolida a leitura de processos litigiosos e sentenças, devendo os meninos aprenderem por meio de

\footnotetext{
${ }^{1}$ Esse termo deve-se ao fato de os índios encontrarem-se em aldeias na região de Guairá, hoje, em terra do estado do Paraná, em "reduções jesuíticas" ou "reduzidos", isto é, presas fáceis de bandeirantes. Os jesuítas espanhóis, para fugirem dos bandeirantes descem para o Sul.

${ }^{2}$ Missões jesuíticas reuniam grupos de religiosos e índios já convertidos à religião católica.
} 


\section{Linguagens \& Cidadania}

manuscritos como o pequeno catecismo do bispo de Montepellier, Carlos Joaquim Colbert (SCHNEIDER, 1993, p. 08).

A lei de 06/11/1772 amparava a criação de escolas conforme uma pesquisa de lugares, que se enquadrassem num projeto de avaliação geral e particular das Comarcas dos Reinos portugueses e do número de habitantes dessas Comarcas, para que o governo pudesse criar Escolas Menores públicas, disponibilizando professores ao ensino das Artes. Como o Rio Grande do Sul ficou fora do rol dessas comarcas, o governador José Marcelino de Figueiredo tomou para si a tarefa de criar escolas as quais foram de efêmera duração no Continente RioGrandense.

Há registro de que, no ano de 1774, foi criada a primeira escola de gramática latina em Porto Alegre, sob a responsabilidade do professor|Tomaz Luiz Osório Júnior, filho do Coronel de Dragões Tomás Luiz Osório (KRAEMER NETO, 1969). Assim, o trabalho de alfabetização em Porto Alegre inicia em 02/08/1778 com Manoel Simões Xavier, considerado "a primeira pessoa investida, aqui, de tão nobre incumbência" (p. 42). Esse professor, que era protegido do governador ${ }^{3}$, tinha a tarefa de ensinar a ler, escrever e contar em sua aula para meninos.

Um pouco mais tarde, em 1790, foi criada a primeira cadeira de Gramática Latina, pelo professor Vitorino Pereira de Coelho, que exerceu a docência em Rio Grande e em Porto Alegre (SCHNEIDER, 1993). Data de 08 de janeiro de 1800, surge a primeira escola particular regular em Porto Alegre para ensinar a ler, escrever, contar e a doutrina cristã. Assim, com a alfabetização instruía-se também sobre o cristianismo. O professor Antônio D'Ávila - conhecido por seu mau humor e pelo gênio forte, chamado de "Amansa-Burros", desenvolvia em suas aulas a leitura de "sentenças judiciárias de processos rumorosos, em que se cominavam penas máximas, não sendo nunca esquecida a que levara à forca o Tiradentes", atividades que não combinam com o trabalho de alfabetização (KRAEMER NETO, 1969, p. 28 e 29).

\footnotetext{
${ }^{3}$ A responsabilidade de nomear professores era um direito privativo da Coroa, que o delegava aos governadores, capitães-generais e bispos.
}

Linguagens \& Cidadania, v. 19, jan./dez., 2017. 


\section{S Linguagens}

Mais tarde, em 15 de outubro de 1807, através de uma provisão do Governador, a aula (particular) de latim, criada pelo padre Thomé Luiz de Souza ${ }^{4}$, em 1880, em Porto Alegre, foi transformada em Aula Régia ${ }^{5}$ (pública). Como não havia recursos suficientes para o pagamento do salário desse professor, a Junta de Administração da Real Fazenda da Capitania de São Pedro do Rio Grande do Sul sugere a instituição de um subsídio literário a fim de resolver essa situação difícil.

Uma Resolução Régia, em 14 de janeiro de 1820, determinava a criação de oito escolas públicas de primeiras letras em Porto Alegre, Rio Grande, Rio Pardo, Santo Antônio da Patrulha, São João das Cachoeiras e nas freguesias de São Francisco de Paula de Pelotas, Senhor Bom Jesus de Triunfo e Nossa Senhora da Conceição de Piratini. Todavia apenas quatro colégios públicos foram efetivamente fundados em: Santo Antônio da Patrulha, Triunfo, Rio Grande e Pelotas que demoraram muito a entrar em atividade por falta de professores e de alunos.

Numa avaliação geral, havia em 1822: (a) apenas uma escola pública de primeiras letras em Porto Alegre; (b) seis colégios particulares primários, e três aulas de latim - uma em Porto Alegre, uma em Rio Grande e outra em Pelotas; (c) um curso de Filosofia Racional, em Porto Alegre.

Em 29 de janeiro de 1823, ocorreu uma reforma do ensino primário no Rio Grande do Sul. Até então, era utilizado o método individual que foi substituído pelo ensino mútuo, criado por Bell na Inglaterra em 1797 e desenvolvido por Joseph Lancaster, que usava monitores-diretores e alguns decuriões ${ }^{6}$ escolhidos dentre os alunos mais adiantados sob a orientação de um professor.

Em 1823, por força da lei, o sistema administrativo das províncias foi modificado: o Imperador nomeou para cada uma delas um Presidente e um Conselho da Presidência. O

\footnotetext{
${ }^{4}$ Foi professor de Antônio Álvares Pereira Coruja, indigente acolhido pelo padre Thomé, autor dos primeiros livros didáticos no Rio Grande do Sul.

${ }^{5}$ A reforma de ensino português provocou a criação, no Brasil, das aulas régias.

${ }^{6} \mathrm{O}$ ensino era constituído de classes e decúrias. As classes com mais de dez alunos dividiam-se em decúrias que contava com um monitor para assessorar a instrução.
}

Linguagens \& Cidadania, v. 19, jan./dez., 2017. 


\section{S Linguagens}

primeiro Presidente da Província de São Pedro do Rio Grande do Sul foi o desembargador José Feliciano Fernandes Pinheiro, empossado em 8 de março de 1824.

A seguir, dá-se continuação ao percurso histórico do ensino no Rio Grande do Sul durante e após o período da Revolução Farroupilha.

\subsection{O ensino durante e após o período da Revolução Farroupilha}

Governos provinciais, - governados por um Conselho da Presidência e por um Presidente, nomeados pelo Imperador, - em 01 de outubro de 1821 substituem, transitoriamente, o sistema de capitanias hereditárias. As províncias seriam administradas por Juntas Governativas escolhidas pelo Colégio Eleitoral das Paróquias, subordinadas diretamente a Lisboa.

Dr. Pereira Ribeiro, presidente do Rio Grande, sanciona a Lei ${ }^{\circ} 14$, de 29/12/1835, que organiza a instrução primária em três graus, determinando o currículo básico de cada um:

a) No primeiro, ensinava-se a ler e escrever pelo método de Lancaster, as quatro operações de Aritmética e os princípios genéricos dos deveres morais e religiosos;

b) No segundo, a Gramática da Língua Nacional, Aritmética até as proporções e suas aplicações no comércio;

c) No terceiro, elementos de geografia, noção de geometria, teoria e prática e suas aplicações ao desenho linear e agrimensura.

Em 29 de dezembro de 1835, o Presidente da província Marciano Pereira Ribeiro sancionou a lei que determinava a criação de uma Escola Normal no Rio Grande do Sul, dispondo inclusive da didática a ser seguida, escola que só se tornou realidade em 1869 .

Há registro que, em 1841, o professor Isidoro Joze Lopes criou um colégio em Porto Alegre e escreveu uma gramática de Língua Nacional e três compêndios de Aritmética (SCHNEIDER, 1993).

No plano político, em 6 de novembro de 1836, o Rio Grande tornou-se República Independente, - separando-se do Império do Brasil - e o Coronel Bento Gonçalves da Silva passa a ser o primeiro presidente dessa República.

Bento Gonçalves reconhece a necessidade de um Gabinete de Leitura - somente da futura Biblioteca Pública, - que se torna realidade somente em 1877. Para tanto, o governo 


\section{Singuagens}

republicano, através de Domingos José de Almeida ${ }^{7}$, oficiou ao presidente da comissão, criada para fazer o levantamento e arrendamento dos bens dos inimigos da República, encaminha correspondência às câmaras de Vereadores do Estado para que angariem obras em seus municípios e a seus amigos, solicitando doações para constituir o acervo do Gabinete de Leitura.

O governo farroupilha para não comprometer a criação de escolas para garantir professor chegou a ponto de reduzir as porções de carne de seus soldados, conforme se lê no Ofício de 05/11/1838, do Ministro da Fazenda, em Piratini, a Bento Gonçalves (SCHNEIDER, 1993). Apesar desses esforços, a instrução pública provincial era considerada atrasada e desorganizada, considerando-se que o território gaúcho passava por um longo período de Revolução Farroupilha.

Em 1842, o Conde de Caxias assume a presidência da província e, em sua gestão, cria vinte e uma escolas. Nessa época, havia cinquenta escolas de instrução primária, das quais trinta e seis eram para meninos e quinze para meninas, número insuficiente para a demanda em educação (SCHNEIDER, 1993).

Em relação ao ensino secundário, havia somente aulas isoladas cujas disciplinas eram livremente escolhidas pelos alunos. Em razão disso, postulava na época a criação de uma Escola Normal, objeto da Lei 446, de 04/01/1860, escola que só entrou em atividade_em 01/05/1869.

Pela Lei 52, de 23/05/1846, foi criado, em Porto Alegre, o Liceu de D. Afonso ${ }^{8}$, que só se tornou realidade em 16/06/1851. Esse Liceu reunia as aulas públicas de instrução secundária de História, Astronomia, Inglês, Desenho e Música. Consta que havia interesse e necessidade de contar, na capital, com uma cadeira de gramática de língua nacional com o objetivo de levar conhecimento aos professores das regras gerais da gramática de língua portuguesa.

A instrução primária ficou separada da secundária por força da Lei Provincial $n^{\circ} 47$, de 13/05/1846, a qual determinava que as disciplinas de francês, geometria, latim e filosofia

\footnotetext{
${ }^{7}$ Domingos José de Almeida era ministro de Estado dos Negócios do Interior, Fazenda e Justiça, da República Rio-Grandense.

${ }^{8}$ D. Pedro II lança a pedra fundamental do futuro Liceu em 01/02/1846.
} 


\section{Singuagens}

fizessem parte do currículo da instrução secundária. E o governo provincial assume responsabilidade do ensino de órfãos e de crianças indígenas.

O Dicionário Geográfico Brasileiro, de Milliet de Saint-Adolphe, registra que, em 1849, havia, em Porto Alegre, aulas públicas de Filosofia, Geometria, Latim, Francês e Taquigrafia, quatro escolas de instrução primária para o sexo masculino e quatro para o feminino. As aulas de Retórica não eram dadas por falta de professor.

Na década de 70, iniciam em Porto Alegre as aulas noturnas para o nível elementar. Em 1872, foi inaugurado o curso noturno da Sociedade Partenon Literário de Porto Alegre.

$\mathrm{O}$ Liceu de D. Afonso encerra suas atividades em fins de $1871_{\text {e }}$ o Ateneu RioGrandense, que o substitui, foi suspenso dois anos mais tarde, Porto Alegre contou apenas com a Escola Normal de instrução primária e as escolas particulares. Mas em 02 de outubro de 1873, o Decreto ${ }^{\circ}$ 5429, cria em Porto Alegre, a Delegacia Especial de Instrução Pública, órgão autorizado para realizar os exames preparatórios - para admissão à matrícula nas academias do Império.

Nessa época, surge o método Abílio, empregado pelo Dr. Abílio Cézar Borges, cuja base era a atividade e a participação do aluno, de forma que a aprendizagem seguisse um percurso que partisse do concreto e fosse para o abstrato, tendo por base o processo intuitivo.

A seguir, tratamos do Movimento de Gramatização no Rio Grande do Sul, já que a questão da língua está ligada ao processo de gramatização brasileira do português.

\section{O MOVIMENTO DE GRAMATIZAÇÃO NO RIO GRANDE DO SUL}

Havia no Sul do País, em fins do século XIX e início do século XX, um significativo movimento de gramatização, considerando-se que Antenor Nascentes atribui a um professor gaúcho - Antônio Alvares Pereira Coruja - o início da "gramaticografia", em 1837, com o “Compêndio de Grammatica da Língua Nacional”, e da "dialetologia” no Brasil, em 1852, com a "Coleção de vocábulos e frases usados na província de São Pedro do Rio Grande do Sul”. A questão da língua nacional está ligada ao processo de gramatização brasileira do português e isso é posto em curso a partir da segunda metade do século XIX. Desde então o Brasil tem seus próprios instrumentos linguísticos de gramatização, diferentes de Portugal. (GUIMARÃES, 2004, p. 24). 


\section{S Linguagens}

Talvez a distância entre Porto Alegre e a Corte ou o espírito de liberdade que dominava o Rio Grande do Sul na época da Revolução Farroupilha tenha levado os professores a se tornarem autossuficientes; ou, ainda, porque fossem incentivados a produzirem seus compêndios, como é o caso do Ato de 19 de fevereiro de 1872, que estimulava os professores da escola Normal a produzir obras didáticas a ponto de receber prêmios, desde que elas fossem aprovadas pelo Conselho Diretor e pela Congregação, conforme excerto desse documento:

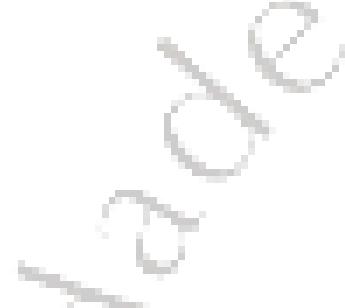

O professor que compuser uma obra que contenha o desenvolvimento completo da matéria de sua cadeira, de sorte que, submetida à apreciação do conselho diretor e congregação dos professores, seja julgada mais apropriada para o uso da mesma cadeira, do que o compêndio então adotado, e possa ser publicada para substituir a este, terá o prêmio de 2000 , que mandará dar-lhe o Presidente da Província (apud SCHNEIDER, 1993, p. 468).

O certo é que tivemos um número bem significativo de gramática produzida no Rio Grande do Sul e que esse acontecimento de gramatização está ligado ao ensino de língua portuguesa, pois todos os nossos gramáticos, - da segunda metade do século XIX e início do século XX, - foram professores que usaram suas gramáticas em suas aulas. Algumas específicas para o ensino primário e ensino fundamental, outras para o ensino mais adiantado; algumas traziam consigo um volume de exercícios. Com esse acontecimento, eles reforçam o vínculo entre a escola e os estudos de língua. O saber - ensino e produção da gramática - dáse num espaço institucional e, conforme afirma Guimarães (2004, p. 15), "ciência e instituição se cruzam num percurso de duas mãos".

Listamos as gramáticas da época: a professor Coruja (1835) que deu início ao movimento de gramatização até a gramática do professor Antônio Fontoura Ilha (1928):

- Compêndio da Grammatica da Língua Nacional, em 1835², de Antônio Alves Pereira Coruja (apelido que passou a fazer parte do nome), dedicado à mocidade riograndense - com diversas reedições;

- Compêndio de Grammatica de Língua Nacional, de Isidoro Joze Lopes, 1841. (Apud SCHNEIDER, 1993);

\footnotetext{
${ }^{9}$ Data citada por Laytano.
} 


\section{Linguagens \& Cidadania}

- Compêndio de grammatica portuguesa, dedicado aos estudantes rio-grandenses, de 1880, do Professor Bibiano Francisco de Almeida, que alcançou quatro edições, uma delas feita no Rio de Janeiro - essa gramática trazia consigo o volume Complemento de grammatica portuguesa ou exercícios de análise fraseológica da oração portuguesa para uso dos estudantes d'esta língua;

- Grammatica Elementar e lições progressivas de composição, 1883, do Professor Hilário Ribeiro, $4^{\circ}$ edição, Pelotas: C. Pinto, para o ensino fundamental. Edição premiada com diploma de $1^{\circ}$ classe e classificada em $1^{\circ}$ lugar pelo júri da Exposição Pedagógica da Corte, em 1883;

- Grammatica primária da língua portuguesa, do Professor André Leão Puente (professor de português, francês, geografia, história e ciências físicas na escola brasileiras), dedicada a seus alunos, editadas pela Livraria do Globo, de Porto Alegre, em $1^{\circ}$ edição 1895 e $2^{\circ}$ em 1903;

- Compêndio de grammatica portuguesa, de Frederico Ernesto de Villeroy, 1904 (3º ed.);

- Livro de exercícios para aprender os elementos de gramática portuguesa, e Sintaxe e grammatica histórica da língua portuguesa, de P. S. (Padre Schneider), 1909;

Língua materna, de Alfredo Clemente Pinto, 1909;

Gramática portuguesa, de Universina de Araújo Bastos, 1909. Dedicada à mocidade rio-grandense e especialmente a seus distintos colegas de magistério;

- Segundo livro de exercícios de português, de Leopoldo Tieböld, 1924;

- Gramática portuguesa: ensino técnico-prático, com 170 exercícios de aplicação, dedicada à sagrada memória de seus pais para o curso secundário, do Professor Antônio Fontoura Ilha, 1928, segunda edição ${ }^{10}$; é também autor de um volume de Arithmetica comercial, ensino essencialmente prático; e de pontos teórico-práticos sobre Escripturação mercantil, para uso de alunos do curso comercial.

Esses autores assumiam, em seus compêndios, uma posição purista de língua, já que no imaginário de então, a gramática normativa tinha a função de ensinar os alunos a falar

\footnotetext{
${ }^{10}$ Não recuperamos a data da primeira edição dessa gramática.
} 


\section{S Linguagens}

corretamente, por isso eram adotadas nas escolas. Mas, pelo que se sabe, o gaúcho não alimentava preconceito em relação à linguagem oral que se distanciava da culta escrita, pois a parte mais substantiva da tradição gauchesca, desde 1777, está escrita em linguagem gauchesca, distante do código culto e próxima da oralidade popular (com algumas exceções, escritas em "lengua general”, como o Santos Veja, de Rafael Obligado); bem ao contrário, a tradição indianista está escrita em português culto sempre, com apenas um ar de imitação da fala índia em determinadas passagens, quando muito.

Trata-se de um problema evidentemente posto pela realidade: à língua do índio não se reconhecia o estatuto de língua propriamente, e mesmo que o fizesse se trataria de outra língua, não o português, o que já seria como foi, argumento definitivo para seu rechaço para fora dos marcos da literatura brasileira que se inventava; da mesma forma, a maneira de falar o português pelos índios não tinha para os escritores qualquer atrativo em si, e até ao contrário, provavelmente tal maneira era vista apenas como um equívoco a ser evitado (FISCHER, 2004, p. 137).

Entre os gaúchos, mesmo que o indivíduo fosse considerado de "poucas letras", se ela fazia versos, - costume na tradição oral popular ibérica, - era considerado um poeta espontâneo e tinha qualidades pata tornar-se um cidadão ele não era discriminado (FISCHER, 2004).

\section{CONSIDERAÇÕES FINAIS}

Neste estudo sobre o movimento de gramatização do Rio Grande do Sul, focalizamos a constituição do saber metalinguístico e a constituição da língua portuguesa nas terras do extremo sul do Brasil - vinculando à constituição de uma língua nacional e seu ensino, às lutas pela posse do território, à vizinhança com os países platinos e à constituição do cidadão.

O isolamento geográfico e econômico em que a Província de São Pedro do Rio Grande do Sul se encontrava do centro do país é um fator que contribuiu para a formação da cidadania e da identidade dos gaúchos no século XIX. Destacamos, nesse sentido, não só o trabalho dos governadores\ presidentes da Província, criando escolas, mas também dos gramáticos escrevendo suas gramáticas nos séculos XIX e XX.

Linguagens \& Cidadania, v. 19, jan./dez., 2017. 


\section{S Linguagens}

Embora, imaginariamente, tenhamos um efeito de unidade de língua, o português falado no Brasil desde aquela época não era mais o mesmo de Portugal, em razão de outras situações enunciativas que remetem às relações sociais de quem as falam - distintas daquelas de Portugal.

Tivemos, desde a segunda metade do século XIX, uma significativa produção e publicação de gramáticas de língua portuguesa no Rio Grande do Sul. De acordo com Orlandi (2002, p. 157),

o que os gramáticos brasileiros estão deslocando é a autoridade de se dizer como é essa língua. Ser autor de uma gramática é ter lugar de responsabilidade como intelectual e ter posição de autoridade em relação à singularidade do português do Brasil.

Tão significativo quanto o trabalho dos governadores, dos presidentes da Província criando escolas, do movimento farrapo para a formação do sentimento de cidadania, pelo sentimento localista muito vivo foi o trabalho dos gramáticos no extremo sul do Brasil em fins do século XIX e princípios do século XX.

\section{REFERÊNCIAS}

FISCHER, L. A. Literatura Gaúcha. Porto Alegre: Leitura XXI, 2004.

GUIMARÃES, E. História da semântica: sujeito, sentido e gramática no Brasil. Campina: Pontes, 2004.

KRAEMER NETO. Nos tempos da escola... Porto Alegre: Livraria Sulina Editora, 1969.

LOPEZ, L. R. Revolução Farroupilha: revisão dos mitos gaúchos. Porto Alegre: Editora Movimento, 1992.

ORLANDI, E. P.; GUIMARÃES, E. Institucionalização dos estudos da linguagem: a disciplinarização das ideias linguísticas. Campinas: Pontes, 2002

PORTO, A. Jesuítas no Sul do Brasil. Vol. IV. Histórias das Missões orientais do Uruguai. Segunda parte. Porto Alegre: Selbach, 1954. 


\section{Linguagens \& Cidadania}

SCHNEIDER, R. P. A instrução pública no Rio Grande do Sul - 1770 - 1889. Porto Alegre: Ed. Universidade/UFRGS/ESTedições, 1993.

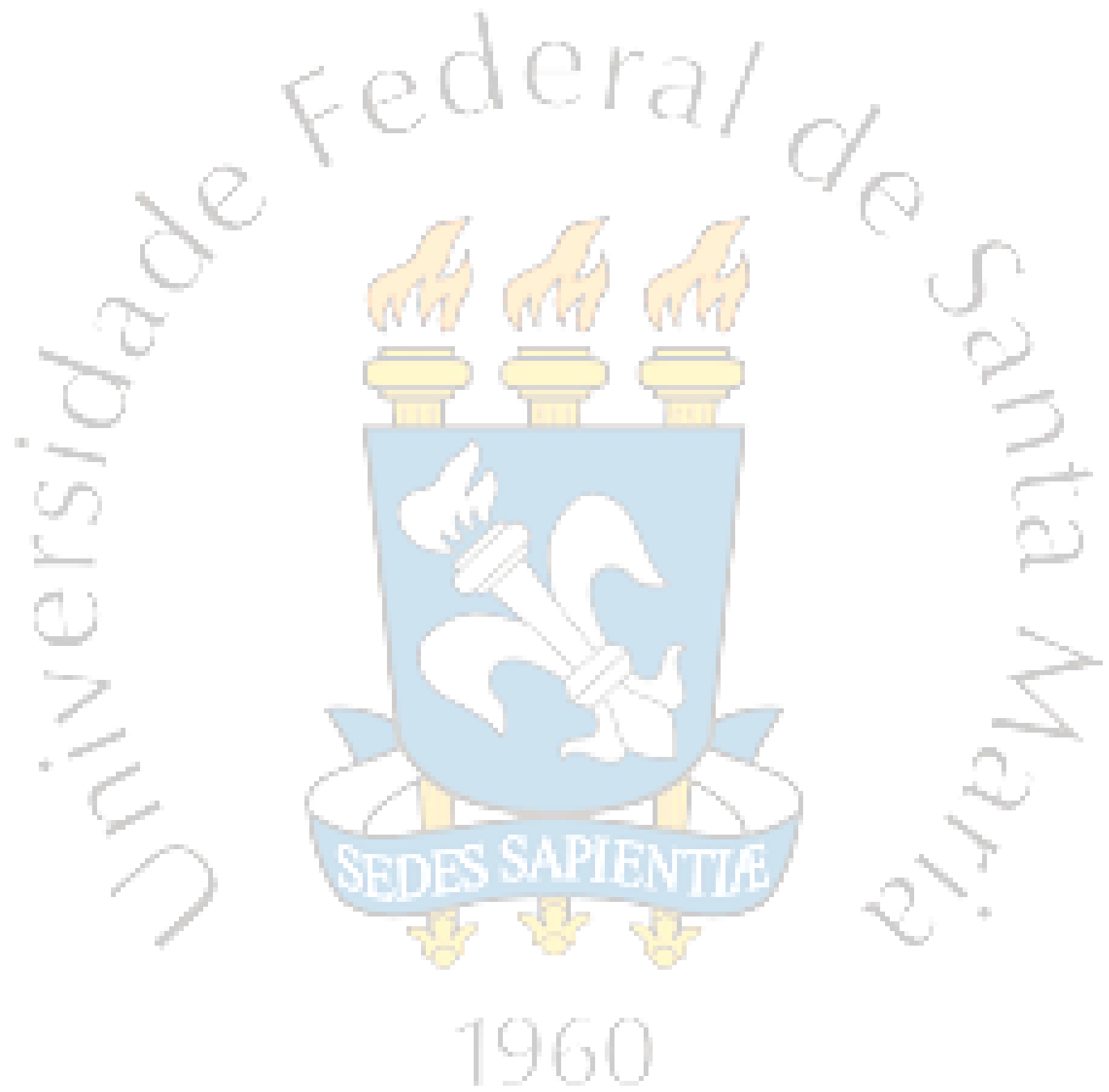

Linguagens \& Cidadania, v. 19, jan./dez., 2017. 